\title{
Anomalous Left Coronary Artery from Pulmonary Artery with Good Ventricular Function in an Adult. A Rare Scenario
}

\author{
Suresh Babu Kale, Rajan Kalaivani, Kurudamannil Abraham Abraham \\ Department of Cardiothoracic Surgery, Apollo Speciality Hospitals, Chennai, India \\ Email: sureshbkale@gmail.com
}

Received 6 June 2014; revised 6 July 2014; accepted 6 August 2014

Copyright $@ 2014$ by authors and Scientific Research Publishing Inc.

This work is licensed under the Creative Commons Attribution International License (CC BY). http://creativecommons.org/licenses/by/4.0/

c) (i) Open Access

\begin{abstract}
Anomalous origin of the left coronary artery from the pulmonary artery (ALCAPA) with preserved ventricular function is a rare congenital coronary artery anomaly when diagnosed in an adult patient and remains an important cause of sudden cardiac death. We report a 42-year-old patient with ALCAPA managed with intrapulmonary interruption of the left main coronary artery (LMCA) ostea and grafting of the LMCA with left internal mammary artery so as to restore antegrade coronary flow. This restores a dual-coronary-artery system and also allows antegrade blood flow as in a normal coronary artery to a large area of viable myocardium. This strategy is simple to accomplish and is more physiological in an anteriorly placed and dilated LMCA as seen in our case.
\end{abstract}

\section{Keywords}

Adult, Congenital Heart Disease, Coronary Arteries, Coronary Artery Bypass Grafting, Arterial Grafts, Cardiopulmonary Bypass

\section{Case Report}

A 42-year-old female was referred for surgical management of ALCAPA after having been evaluated for angina on exertion lasting for two months. Tread-mill test was positive for inducible ischemia and transthoracic echocardiogram showed mild mitral regurgitation and normal left ventricular function with no wall motion abnormalities. Coronary Angiogram revealed ALCAPA with run-off of the coronary dye into the pulmonary circuit. Multislice computerized tomography (CT) showed a dilated left main coronary artery (LMCA) entering the main pulmonary artery (MPA) along with a tortuous and markedly dilated right coronary artery arising from the aorta (Figure 1). Twelve lead electrocardiogram and biochemical laboratory investigations were within normal 
limits. A standard median sternotomy was performed and markedly dilated right and left coronary arteries along with dilated inter-coronary collateral arteries were seen along the epicardial surface of the heart. The LMCA was long, anteriorly placed and seen clearly entering the MPA. A thrill was palpable on the MPA at the site of LMCA insertion. The LMCA arose from the left inferolateral aspect of the MPA and then coursed toward the interventricular groove, branching into the left anterior descending and circumflex arteries. Cardiopulmonary bypass (CPB) was established with aorto-bicaval cannulation and the left ventricle was vented through the right superior pulmonary vein. The MPA was opened longitudinally with the heart beating amidst stay sutures. The fistulous opening of the LMCA into the pulmonary artery sinus was identified and suture closed with fresh pericardial patch using 5 - 0 prolene. The skeletonised left internal mammary artery (LIMA), harvested earlier, was grafted to the LMCA near its insertion into MPA as it was anterior and easily accessible. The LIMA, after anastomosis was allowed to flow and leaks across the fistulous opening of the LMCA into the MPA was checked. The MPA was closed and the patient weaned off bypass without difficulty. The whole procedure was done with the heart beating whilst on CPB and at normothermia. The postoperative period was uneventful.

Computerised tomography angiogram performed prior to discharge from the hospital showed a patent LIMA, closed fistulous opening of the LMCA into MPA (Figure 2) and preserved ventricular function. The patient was asymptomatic and clinically doing well at the time of this writing.

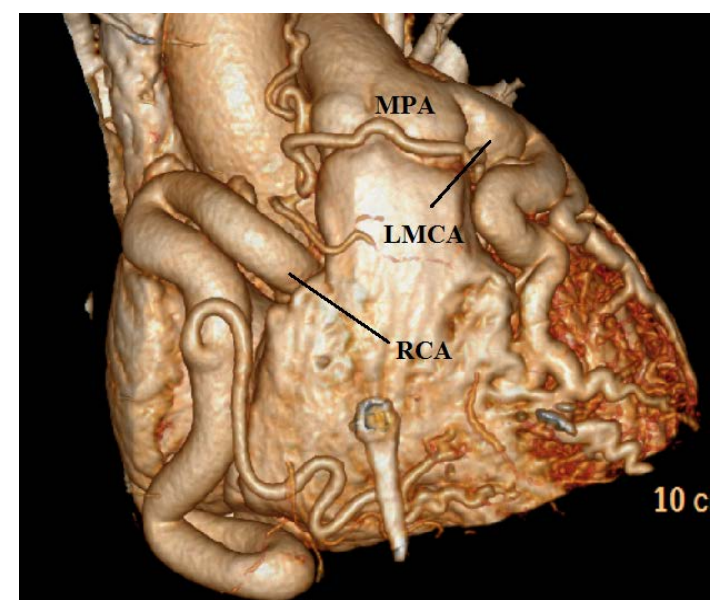

Figure 1. Reconstructed CT angiogram shows a markedly dilated right and left coronary artery and the left main coronary artery entering the main pulmonary artery.

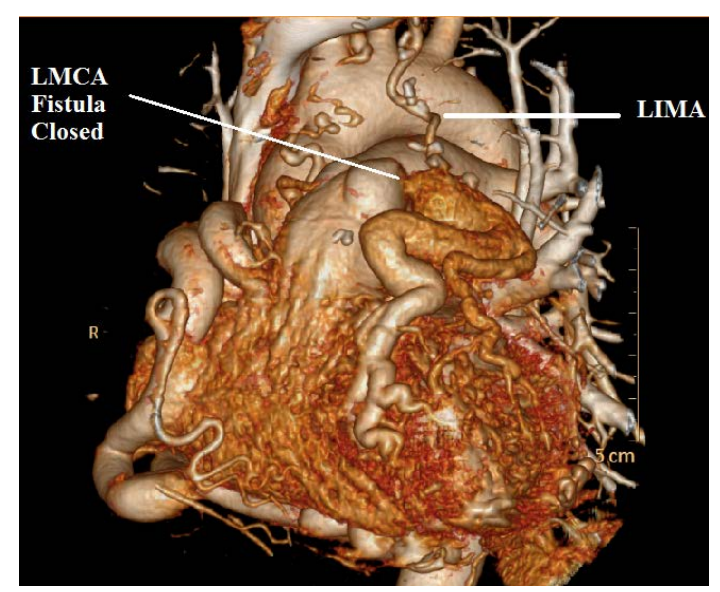

Figure 2. Postoperative CT angiogram showing the closed fistulous opening and patent internal mammary artery. 


\section{Comment}

Anomalous origin of the left coronary artery from the pulmonary artery (ALCAPA) syndrome affects one of every 300,000 live births [1] and accounts for $0.25 \%$ to $0.5 \%$ of all congenital heart defects. The pulmonary pressure is low in adults and allows for flow reversal from left coronary artery of the fully oxygenated blood into the MPA rather than into the high-resistance myocardial circulation. This results in a coronary steal phenomenon akin to a left-to-right shunt at the level of MPA and leads to abnormal left ventricular perfusion. If left untreated, up to $90 \%$ of patients die within the first year of life. In patients who live to adulthood, ALCAPA syndrome may cause myocardial infarction, left ventricular dysfunction, and mitral regurgitation or silent myocardial ischemia and sudden cardiac death [2] [3]. Early diagnosis and prompt surgical intervention with the aim of restoring a two-coronary-artery circulatory system have excellent results and lead to gradual myocardial recovery.

Significant collateral blood supply is from the right coronary artery and in some cases, bronchial circulation allows the patient to survive into late adulthood. Adults with ALCAPA may remain asymptomatic despite subclinical myocardial ischemia and they become symptomatic only when myocardial steal continues [2]. Without surgical intervention, they are prone to malignant ventricular arrhythmias and sudden death secondary to myocardial ischemia and global cardiomyopathy with an estimated incidence of $80 \%$ to $90 \%$ at a mean age of 35 years [3] [4]. The diagnosis is often made by two-dimensional echocardiography with direct visualization of the abnormal origin of the left coronary artery and retrograde flow into the pulmonary artery. However, gated multidetector CT angiography offers excellent spatial resolution required to assess small vessels such as the coronary arteries despite its inability to assess flow and relatively high radiation dose.

Surgical correction is standard and justified as soon as a diagnosis is made, except in a few asymptomatic patients at the extremes of age [5]. Surgery enables correction of chronic subendocardial ischemia and recovery of ventricular function and reduces the risk for malignant dysrhythmias and sudden death. There are several surgical approaches including the one coronary system, two-coronary system repairs and cardiac transplantation [2] [5]-[8]. Two-coronary system repairs are preferred and include coronary button transfer, intrapulmonary tunnel procedure and placement of a coronary artery bypass graft combined with interruption of the origin of LMCA. All these techniques are effective so long as there is potential for myocardial recovery. In adults, direct reimplantation is technically difficult and hazardous because of unfavourable anatomy, increased coronary artery friability, diminished vessel elasticity for mobilization, and the potential for tearing and resultant catastrophic bleeding [1]-[3] [7].

Intrapulmonary tunnelling has been associated with pulmonary valvular dysfunction, baffle obstruction, and bleeding [1] [7]. The experiences of these procedures in adults are limited and hence we like others [2] [3] preferred interruption of LMCA at its origin from the MPA combined with coronary bypass graft placement by using the internal mammary artery. Although saphenous vein grafts have been used before, they are not recommended because of their poor patency rates. Coronary artery bypass grafting with the LIMA is judicious, simple, and safe option in adults with ALCAPA with proven excellent long-term patency. The LMCA in our case was long, anterior, and easily accessible to place a graft and this allows physiologic antegrade flow into both the branches of the left system supplying a large area of myocardium. In this patient, the LMCA was large and dilated and allowed for a satisfactory anastomosis. The torrential flow across the coronaries should not be underestimated and the procedure is best done on-pump. Restoration of a dual-coronary system will prevent further ischemia and arrhythmias of acute ischemic origin.

\section{References}

[1] Dodge-Khatmi, A., Mavroudis, C., Backer, C.L. (2002) Anomalous Origin of the Left Coronary Artery from the Pulmonary Artery: Collective Review of Surgical Therapy. The Annals of Thoracic Surgery, 74, 946-955. http://dx.doi.org/10.1016/S0003-4975(02)03633-0

[2] Moodie, D.S., Fyfe, D., Gill, C.C., et al. (1983) Anomalous Origin of the Left Coronary Artery from the Pulmonary Artery (Bland-White-Garland Syndrome) in Adult Patients: Longterm Follow-Up after Surgery. American Heart Journal, 106, 381-388. http://dx.doi.org/10.1016/0002-8703(83)90207-7

[3] Alexi-Meskishvili, V., Berger, F., Weng, Y., et al. (1995) Anomalous Origin of the Left Coronary Artery from the Pulmonary Artery in Adults. Journal of Cardiac Surgery, 10, 309-315. http://dx.doi.org/10.1111/j.1540-8191.1995.tb00617.x

[4] Cherian, K.M., Bharati, S. and Rao, S.G. (1994) Surgical Correction of Anomalous Origin of the Left Coronary Artery 
from the Pulmonary Artery. Journal of Cardiac Surgery, 9, 381-391.

http://dx.doi.org/10.1111/j.1540-8191.1994.tb00866.x

[5] Fierens, C., Budts, W., Denef, B., et al. (2000) A 72-Year-Old Woman with ALCAPA. Heart, 83, E2. http://dx.doi.org/10.1136/heart.83.1.e2

[6] Sivasubramanian, S., Krishnamurthy, S.M., Thirumalai, P., et al. (1996) Anomalous Origin of the Left Coronary Artery from Pulmonary Artery: Is Reconstruction of a Double Coronary Artery System Always Necessary? The Journal of Thoracic and Cardiovascular Surgery, 111, 901-903. http://dx.doi.org/10.1016/S0022-5223(96)70357-4

[7] Chan, R.K., Hare, D.L. and Buxton, B.F. (1995) Anomalous Left Main Coronary Artery Arising from the Pulmonary Artery in an Adult: Treatment by Internal Mammary Artery Grafting. Journal of Thoracic and Cardiovascular Surgery, 109, 393-394. http://dx.doi.org/10.1016/S0022-5223(95)70404-3

[8] Nair, K.K., Zisman, L.S., Lader, E., et al. (2003) Heart Transplant for Anomalous Origin of Left Coronary Artery from Pulmonary Artery. The Annals of Thoracic Surgery, 75, 282-284. http://dx.doi.org/10.1016/S0003-4975(02)04279-0 
Scientific Research Publishing (SCIRP) is one of the largest Open Access journal publishers. It is currently publishing more than 200 open access, online, peer-reviewed journals covering a wide range of academic disciplines. SCIRP serves the worldwide academic communities and contributes to the progress and application of science with its publication.

Other selected journals from SCIRP are listed as below. Submit your manuscript to us via either submit@scirp.org or Online Submission Portal.
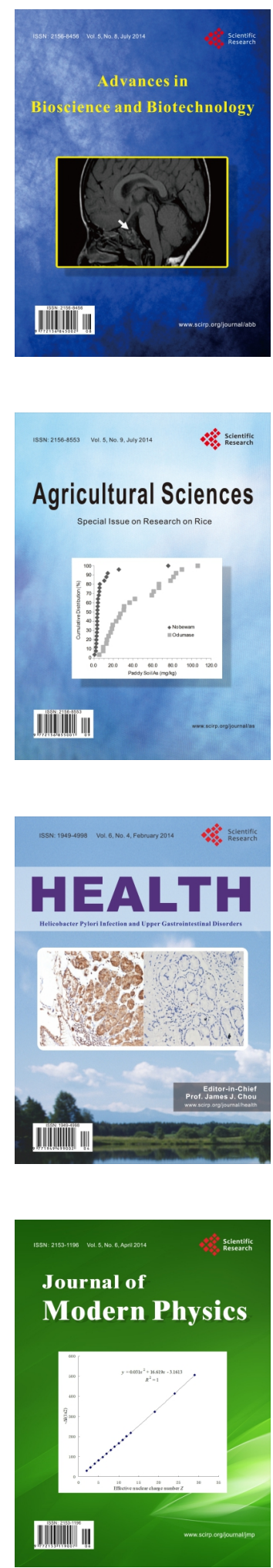
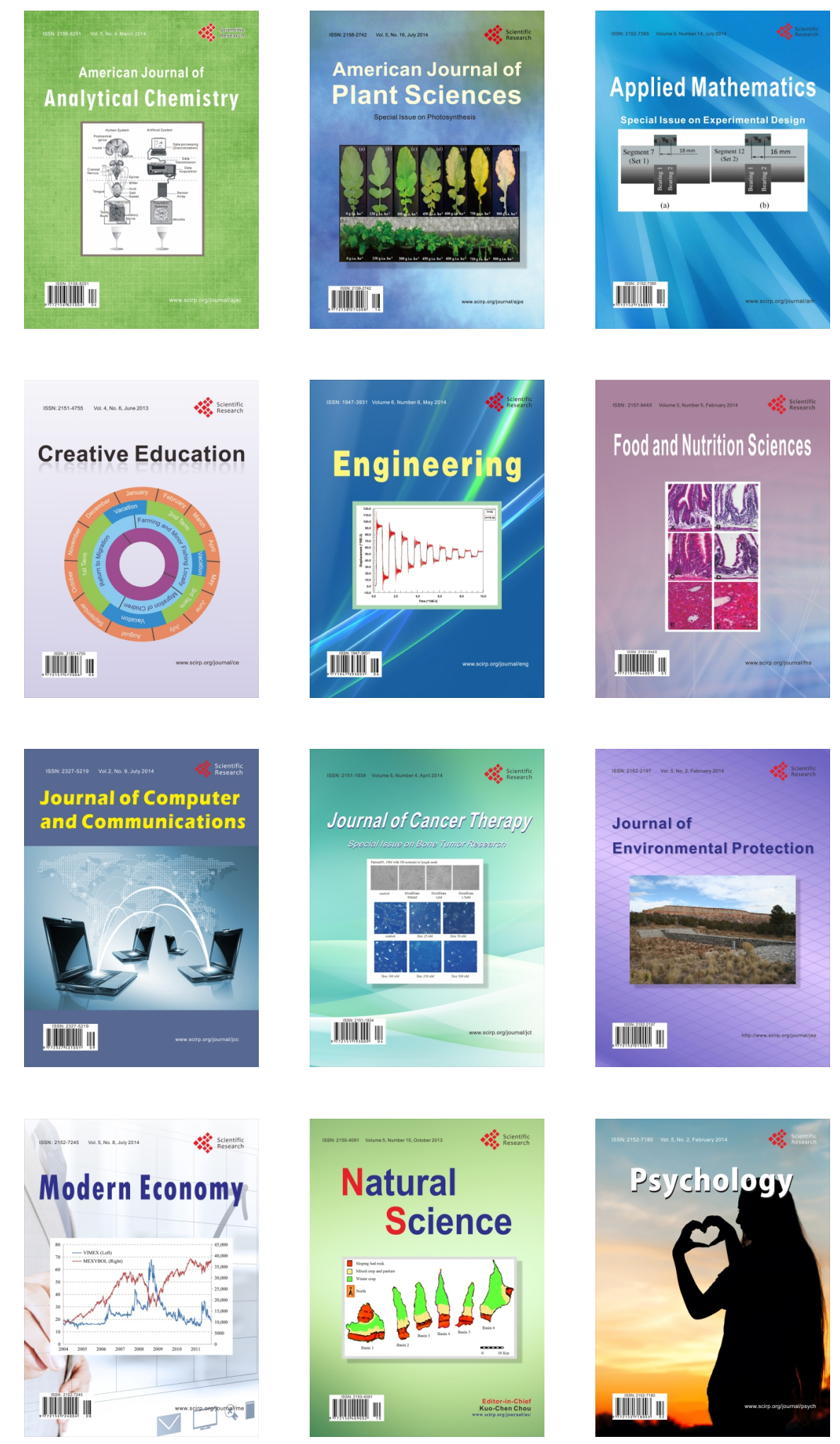